Abbreviated Key Title: Sch J Med Case Rep

ISSN 2347-9507 (Print) | ISSN 2347-6559 (Online)

Journal homepage: https://saspublishers.com

\title{
Giant Aneurysmal Presentation of Chronic Type a Aortic Dissection
}

El-Alaoui Mohamed*, Zalle Issaka, Fuzellier Jean Francois, Vola Marco, Salvatore Campisi

Cardiovascular Surgery Departement, University Hospital of Saint Etienne, Avenue Albert Raimond, 42270 Saint-Priest-en-Jarez, France

DOI: $10.36347 /$ sjmcr.2021.v09i02.019

| Received: 18.01.2021 | Accepted: 01.02.2021 | Published: 27.02.2021

*Corresponding author: El-Alaoui Mohamed

Abstract

Case Report

Chronic evolution of type A acute aortic dissection is not frequently observed. We report a case of an exceptional giant aneurismal presentation of chronic type A aortic dissection in a patient with symptoms of aortic valve insufficiency and heart failure.

Keywords: Giant aneurismal, aortic dissection.

Copyright $(\mathcal{C} 2021$ The Author(s): This is an open-access article distributed under the terms of the Creative Commons Attribution 4.0 International License (CC BY-NC 4.0) which permits unrestricted use, distribution, and reproduction in any medium for non-commercial use provided the original author and source are credited.

\section{INTRODUCTION}

Chronic type A aortic dissection is a rare pathology with peculiar clinical, anatomical and diagnostic features. We report a case of an exceptional giant aneurismal presentation of chronic type A aortic dissection.

\section{CASE Reports}

A 47 - years old male presented to his cardiologist for a dyspnea persistent by 10 days, in his medical history the only cardiovascular risk factors were smoking and obesity, there was any notion of acute or chronic chest pain. On clinical examination he presented normal blood pressure and mild oedema of the lower limbs. The cardiac auscultation revealed a 4/6 continuous murmur, best heard at the apex. Echocardiographic control found a dilated left ventricle with a normal systolic function but a giant aneurysm of the ascending aorta associated with severe aortic regurgitation, the aortic valve was tricuspid. Thus, the patient was referred immediately to emergency room of our institution, where the computed tomography scan clearly revealed a chronic Stanford type A aortic dissection with a huge aneurismal dilatation of a dissected ascending aorta (Figure-1: Diam max 11.1 $\mathrm{cm}$ ). The patient underwent emergency operation of replacement of the native aortic valve, aortic root, ascending thoracic aorta and aortic arch with coronary artery re- implantation according to bental technique by median sternotomy. Intraoperatively we found no pericardial effusion and a giant dissected ascending aorta compressing the nearby anatomical structures, the macroscopic appearance of biological tissues was typical of a chronic dissection of the aortic wall (Figure-2). Postoperative course was uneventful and the patient was discharged on 7 th postoperative day.

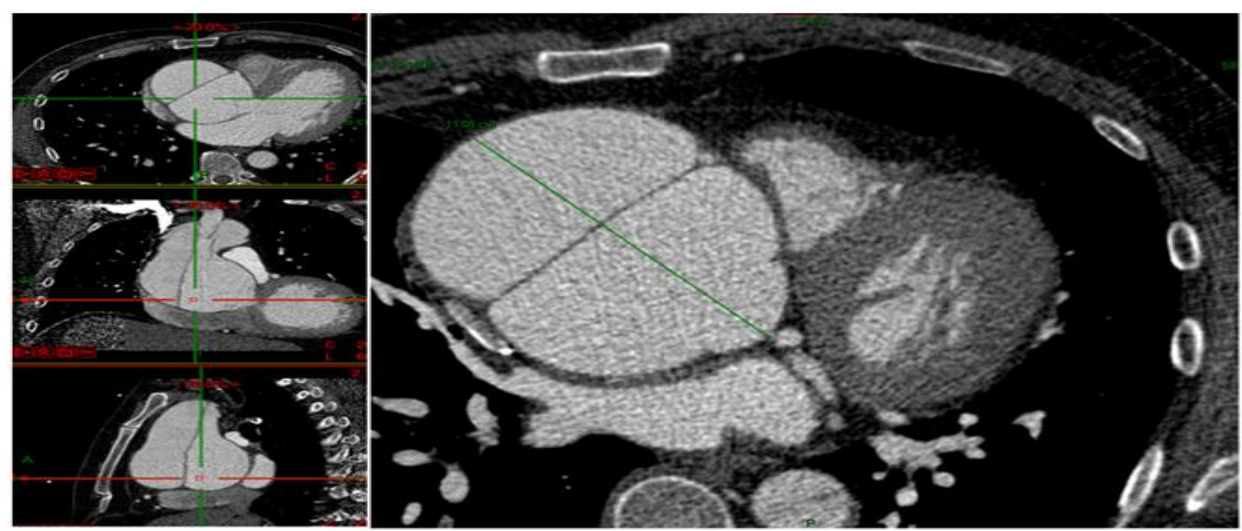

Fig-1: Sagittal, frontal and cross section of chest computed tomography showing a huge Aneurismal dissected ascending thoracic aorta 


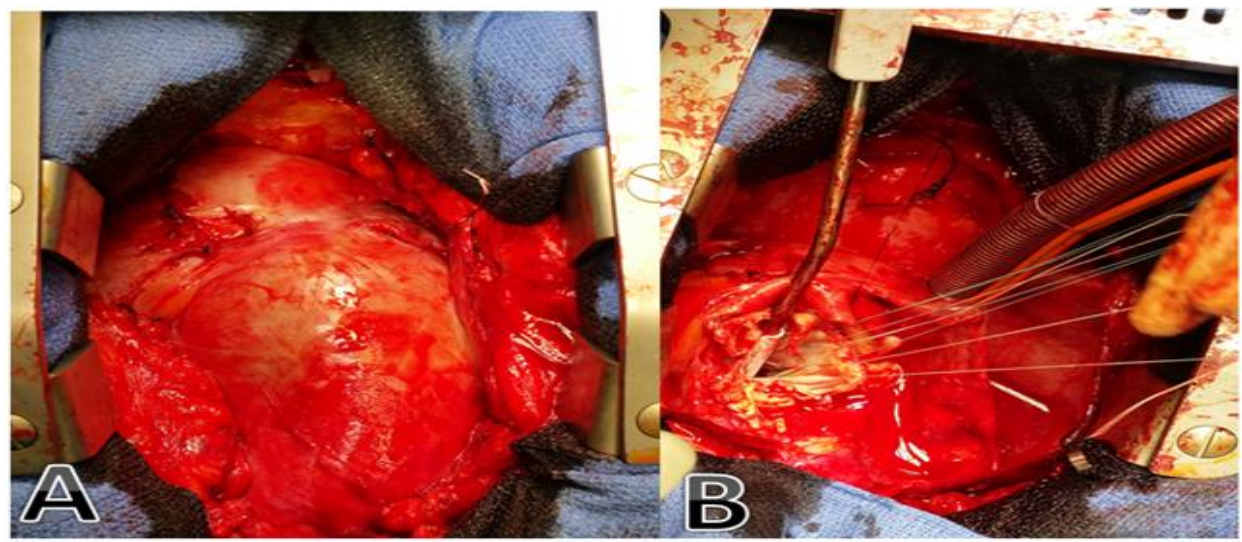

Fig-2: Intraoperative views: A) The aorta compressing the nearby anatomical structures. B) The ascending thoracic aorta opened during cardiopulmonary bypass and cardioplegic cardiac arrest revealing the excepltionally thickened and resistant aortic wall tissues

\section{DISCUSSION}

In the case of an untreated Stanford type A aortic dissection only about one quarter of patients survive after the initial phase. In consideration of this possible biologic election process Stanford type A aortic dissection has been classified in two groups: aortic dissection is defined as 'acute' when the disease is diagnosed 14 days or fewer from onset of initial symptoms and 'chronic' when the pathology comes to the clinical attention more than 14 days from symptom onset. Chronic evolution of type A acute aortic dissection is not frequently observed, because of an extremely high risk of mortality, usually asymptomatic and incidentally discovered. Surgical repair is recommended in the case of an aortic diameter exceeding $55 \mathrm{~mm}$, moderate or severe aortic valve insufficiency. A rapid aortic diameter growing (> 0.5 $\mathbf{c m} / \mathbf{y}$ ), new onset of chest pain or neurologic disorders can guide clinical decision making too. The management and surgical timing are debated, in the series presented by Rylski et al., [1] the emergency surgical treatment is recommended in patients with new or uncontrolled chest pain or hemodinamicaly unstable. Surgery may be deffered within 48 hours in case of asymptomatic patients with ascending aorta aneurysm or severe aortic insufficiency and symptoms of heart failure. The very few remnant patients could strictly be controlled by close CT scan follow up. In literature there are a few anecdotal case reports $[2,3]$ concerning type A aortic chronic dissection, so the surgical results are not based on large series. Certainly, the patients who survive the acute phase of type A aortic dissection without surgery are highly selected patients in whom it is impossible to indicate the exact time when the aorta dissected. Thus, they have the time for experiencing a progressive dilatation of the dissected proximal aorta and progressive aortic valve insufficiency. Longlasting aortic valve insufficiency is not infrequently associated to significant and surprising structural changes of the aortic root, including stretching of the valvular leaflet and alteration of aortic valve and annulus geometry. The chronic nature of this process is responsible of the typical surgical features of chronic type A aortic dissection, namely the strong thickened of the aortic wall tissue and this could contribute to promote sealing of surgical sutures.

\section{CONCLUSION}

In the majority of patients with chronic type A dissection, surgical correction with replacement of dissected aorta and aortic valve repair or replacement could be performed effectively and safely.

\section{REFERENCES}

1. Weymann A, Schmack B, Karck M, Szabo G. Giant Pseudoaneurysm of the Ascnding Aorta Caused by Chronic Stanfortd Type A Aortic Dissection. Can J Cardiol. 2011 Nov-Dec; 27(6):871.

2. Ong B, Harvey M, Cave G. Images in emergency medicine: giant ascending aortic aneurysm dissetion with hemopericardium. World J Emerg Med. 2012; 3(3): 235-6.

3. Rylski B, Milewski RK, Bavaria JE, Branchetti E, Vallabhajosyula P, Szeto WY, Desai ND. Outcomes of surgery for chronic type A aortic dissection. The Annals of thoracic surgery. 2015 Jan 1;99(1):88-93. 